\title{
A randomized, controlled trial of oral versus intravenous fluids for lowering blood glucose in emergency department patients with hyperglycemia
}

\author{
Sanjay Arora, MD; Marc A. Probst, MD; Laura Andrews, MD; Marissa Camilion, MD; \\ Andrew Grock, MD; Gregory Hayward, MD; Michael Menchine, MD, MPH
}

\section{ABSTRACT}

Objectives: Blood glucose can be lowered via insulin and/or fluid administration. Insulin, although efficacious, can cause hypoglycemia and hypokalemia. Fluids do not cause hypoglycemia or hypokalemia, but the most effective route of fluid administration has not been well described. This study compared the efficacy and safety of oral versus intravenous fluids for reducing blood glucose in patients with hyperglycemia.

Methods: We conducted a prospective, nonblinded, randomized, controlled trial. Inclusion criteria were blood glucose $>13.9 \mathrm{mmol} / \mathrm{L}$, age > 18 years, and ability to tolerate oral fluids. Subjects were excluded for critical illness, contraindication to fluids, and/or hyperglycemia therapy prior to enrolment. Subjects were randomized to receive oral bottled water or intravenous normal saline (maximum 2 L) over 2 hours. The primary outcome of interest was a change in blood glucose at 2 hours across treatment arms.

Results: The 48 subjects were randomized. Baseline blood glucose levels and total amount of fluid received were similar between the two groups. The mean decrease in blood glucose at 2 hours was similar for both treatment arms: a mean decrease of $3.4 \mathrm{mmol} / \mathrm{L}(20.2 \mathrm{mmol} / \mathrm{L}$ to $16.8 \mathrm{mmol} / \mathrm{L})$ in the oral fluid group versus a mean decrease of $4.0 \mathrm{mmol} / \mathrm{L}$ ( $19.7 \mathrm{mmol} / \mathrm{L}$ to $15.7 \mathrm{mmol} / \mathrm{L}$ ) in the intravenous fluid group. The mean difference between groups was $-0.6 \mathrm{mmol} / \mathrm{L}(95 \%$ confidence interval $-2.3-1.2 ; p=0.51$ ). No adverse events were observed in either group.

Conclusion: In this unblinded randomized trial, oral and intravenous fluids were equally efficacious in lowering blood glucose levels in stable hyperglycemic patients and no adverse events were noted. Physicians should be mindful that, although similar, the reduction in blood glucose was modest in both groups.
RÉSUMÉ

Objectifs: II est possible d'abaisser la glycémie par l'insuline et/ou par l'administration de liquides. Bien que l'insuline soit efficace, elle peut causer de l'hypoglycémie ou de I'hypokaliémie. Les liquides, eux, ne causent pas ces problèmes, mais on ne connaît très bien la meilleure voie d'administration. L'étude visait à comparer l'efficacité et l'innocuité de l'administration de liquides par voie orale ou par voie intraveineuse pour abaisser le taux de sucre dans le sang chez des patients hyperglycémiques.

Méthodes: II s'agit d'un essai comparatif, prospectif, à répartition aléatoire, mené au su des parties. Les critères de sélection comprenaient une glycémie $>13.9 \mathrm{mmol} / \mathrm{L}$, un âge $>18$ ans et la capacité de tolérer les liquides par voie orale. Les critères d'exclusion comprenaient une maladie très grave, des contreindications à l'administration de liquides et/ou un traitement hypoglycémiant avant l'entrée dans I'essai. Les sujets recevaient au hasard soit de l'eau en bouteille, à prendre par voie orale, soit une solution physiologique salée, administrée par voie intraveineuse (maximum: $2 \mathrm{~L}$ ) sur une période de 2 heures. Le principal critère d'évaluation était la valeur de la glycémie au bout de 2 heures dans les deux groupes de traitement.

Résultats: Quarante-huit sujets ont été sélectionnés et dirigés au hasard vers l'un des deux groupes de traitement. La glycémie de départ et la quantité totale de liquides administrés étaient comparables dans les deux groupes. La diminution moyenne de la glycémie au bout de 2 heures était du même ordre de grandeur dans les deux groupes, soit une réduction de $3.4 \mathrm{mmol} / \mathrm{L}(20.2 \mathrm{mmol} / \mathrm{L}$ à $16.8 \mathrm{mmol} / \mathrm{L})$ dans le groupe de traitement par voie orale contre une réduction de $4.0 \mathrm{mmol} / \mathrm{L}$ (19.7 mmol/L à $15.7 \mathrm{mmol} / \mathrm{L})$ dans le groupe de traitement par voie intraveineuse. L'écart moyen entre les deux groupes était de $-0.6 \mathrm{mmol} / \mathrm{L}$ (intervalle de confiance à 95\%: $-2.3-1.2 ; p=0.51$ ). Aucun événement indésirable n'a été observé dans l'un ou l'autre des groupes.

From the Department of Emergency Medicine, Keck School of Medicine at the University of Southern California, Los Angeles, CA.

Correspondence to: Dr. Sanjay Arora, Department of Emergency Medicine, Keck School of Medicine at the University of Southern California, 1200 North State Street, Room 1011, Los Angeles, CA 90033; sanjay.arora@usc.edu.

This article has been peer reviewed. 
Conclusion: Dans cet essai à répartition aléatoire, mené au su des parties, I'administration de liquides par voie orale ou par voie intraveineuse a permis d'abaisser quelque peu le taux de sucre dans le sang, et ce, de manière comparable, chez des patients hyperglycémiques, stables; par ailleurs, aucun événement indésirable n'a été observé. Les médecins devraient toutefois se rappeler que l'abaissement de la glycémie, bien qu'il fût comparable, était faible dans les deux groupes.

Keywords: diabetes, fluid administration, hyperglycemia
Diabetes affects over 23 million people in North America, including $6.8 \%$ of the Canadian population. ${ }^{1,2}$ The number of North Americans with diabetes is increasing, and this rise in disease burden has a direct impact on the emergency department (ED), evidenced by a $5.6 \%$ relative annual increase in the proportion of ED visits that were diabetes related from 1997 to 2007. ${ }^{3}$ Hyperglycemia is a common presenting situation in EDs, but the vast majority of these patients are not experiencing a true metabolic emergency (e.g., diabetic ketoacidosis [DKA] $).{ }^{4} \mathrm{We}$ are left with a large number of patients with hyperglycemia and not in DKA, but the optimal management strategy for these patients has not been well described. Although there is significant variability among practitioners as to exactly how low blood glucose levels should be prior to discharge and whether asymptomatic hyperglycemia needs an acute intervention, most emergency physicians feel compelled to lower a hyperglycemic patient's blood glucose below an individualized, but often arbitrary, threshold.

The two primary methods to reduce blood glucose are insulin and/or fluid administration. Insulin, although efficacious, has been shown to use greater nursing resources, is associated with a $7.4 \%$ rate of hypoglycemia requiring intervention, and can precipitate hypokalemia. ${ }^{6,7}$ Although fluid administration also involves nursing resources, it does not cause hypoglycemia or hypokalemia. It is not currently known if oral or intravenous (IV) fluid is superior for lowering blood glucose levels. In general, oral fluids are safer, more easily initiated by nurses, and less invasive than IV fluids. ${ }^{8}$ For example, in children with mild to moderate dehydration secondary to acute gastroenteritis, oral fluids are used effectively and are considered the preferred therapy. ${ }^{8,9}$ In this prospective, randomized, controlled trial, we compared the efficacy of oral bottled water versus IV normal saline to lower blood glucose in stable adult ED patients with hyperglycemia.

\section{METHODS}

\section{Study design}

This was a prospective, nonblinded, randomized, controlled trial, approved by the local Institutional Review Board. Written informed consent was obtained from all study participants. The trial was registered with ClinicalTrials.gov \# HS-10-00223.

\section{Study setting and population}

This trial was conducted in the ED at Los Angeles County Medical Center at the University of Southern California, a large, urban, county ED with over 170,000 annual visits. The cohort studied represents a convenience sample of ED patients presenting between the hours of 9 am and 5 pm Monday though Friday from January to March 2011.

\section{Study protocol}

As there is no previous literature in this population to estimate a treatment effect, we did not conduct a formal sample size calculation. Sample size was based on available resources and what would reasonably generate data for future studies. Subjects were enrolled on 43 days during the study period based on research assistant availability. Research assistants screened the electronic patient tracking board and conferred with triage nurses to identify patients with measured triage capillary blood glucose $\geq 13.9 \mathrm{mmol} / \mathrm{L}$. Patients at our institution receive a blood glucose measurement at triage if they have a history (past or present) of diabetes, are taking oral hypoglycemic medications and/or insulin, or have symptoms suggestive of hyperglycemia (e.g., polyuria, polydipsia, weight loss, altered mental status) or if the triage nurse suspects hyperglycemia. The Precision Xtra meter (Medisense/ Abbott Laboratories, North Chicago, IL) was used to obtain all point-of-care capillary blood glucose 
measurements. Patients presenting to the ED for any complaint with blood glucose $>13.9 \mathrm{mmol} / \mathrm{L}$ were approached for enrolment. Additional inclusion criteria included age $>18$ years, ability to tolerate oral fluids, and ability to provide written informed consent in English or Spanish. Exclusion criteria included altered mental status, critical illness, and/or contraindication to receiving fluids (e.g., renal failure, fluid overload, congestive heart failure). We also excluded patients who had received fluid therapy in the ED or waiting room prior to randomization and patients who had received short-acting insulin therapy or had taken their own insulin 2 hours prior to randomization. It would be impossible to measure the effect of the intervention with these confounders. We further excluded patients who exceeded the testing range $(\geq 33.3 \mathrm{mmol} / \mathrm{L}$ ) of the Precision Xtra meter and had a reading of "critical high" as we would be unable to report the initial blood glucose and subsequent change in blood glucose over time.

After consent and enrolment, patients were randomized to one of two treatment arms: oral fluid versus IV fluid. We used variable block-size randomization with sealed, opaque envelopes to ensure allocation concealment. The randomization sequence was generated by Stata 11.0 (StataCorp., College Station, TX). The envelopes were not opened by the research assistants until after eligibility was confirmed and written consent was obtained. Patients randomized to oral fluids received bottled water to drink at a rate of approximately $1 \mathrm{~L}$ per hour or as tolerated, and the IV fluids group was given normal saline via an IV line. Both groups received a maximum of $2 \mathrm{~L}$ over the 2-hour study period.

\section{Measurements}

We recorded demographic and clinical information for each patient, including the reason for the visit, age, gender, race, chief complaint, history of diabetes, insulin use, and compliance with diabetes medications within the last 3 days. The volume of fluid received and blood glucose were measured at 0, 30, 60, 90, and 120 minutes. Research assistants also assessed the patients every 30 minutes for adverse effects, including shortness of breath, nausea, vomiting, and/or change in mental status. If any adverse effects were noted, the protocol was to immediately notify the triage nurse and treating physician on duty for further management instructions. All results were recorded on a Microsoft Excel spreadsheet (Microsoft Corp., Redmond, WA).

\section{Data analysis}

Demographic and clinical variables were graphically analyzed, and descriptive statistics were generated. The primary study outcome was mean difference in blood glucose at 2 hours across treatment arms assessed using the Student $t$-test of significance and intention-to-treat principles. Secondary end points included the mean decrease in blood glucose at 30,60, and 90 minutes and the presence of adverse events related to fluid administration in either group.

\section{RESULTS}

Of 115 patients approached, 50 were determined to be ineligible (7 with a "critical high" blood glucose reading at triage, 19 who had already received fluids, 5 who were previously treated with insulin, 10 who had a contraindication to fluid administration, 7 who were critically ill, and 2 who were unable to provide consent due to a language barrier), leaving 65 eligible for enrolment. Of these, 48 (74\%) agreed to participate. The mean initial blood glucose for all enrolled patients was $20 \mathrm{mmol} / \mathrm{L}$ (SD 93.1). Of the 48 enrolled subjects, 25 were randomized to oral fluid administration therapy and 23 were randomized to IV hydration with normal saline. The three most common reasons for the visit were extremity complaints $(n=15: 10 \mathrm{IV}$ and 5 oral), abdominal or flank pain $(n=9: 7 \mathrm{IV}$ and 2 oral), and referral for elevated blood glucose $(n=6: 4$ IV and 2 oral). Age, initial capillary blood glucose, ethnicity, proportion of patients with known diabetes, and proportion of patients using insulin were similar between the treatment groups. Full collected demographic and clinical information for each group is shown in Table 1.

The mean decrease in blood glucose at 2 hours was similar for both treatment arms: a mean decrease of $3.4 \mathrm{mmol} / \mathrm{L}, \mathrm{SD}=3.0 \mathrm{mmol} / \mathrm{L}$ (from a mean of $20.2 \mathrm{mmol} / \mathrm{L}$ to a mean of $16.8 \mathrm{mmol} / \mathrm{L})$, in the oral fluid group versus a mean decrease of $4 \mathrm{mmol} / \mathrm{L}, \mathrm{SD}=$ $3.0 \mathrm{mmol} / \mathrm{L}$ (from $19.7 \mathrm{mmol} / \mathrm{L}$ to $15.7 \mathrm{mmol} / \mathrm{L}$ ), in the IV fluid group. The difference between groups was $-0.6 \mathrm{mmol} / \mathrm{L}$ (95\% confidence interval $-2.3-1.2$; $p=0.51)$. The mean decreases in blood glucose were also similar at 30,60, and 90 minutes across treatment 


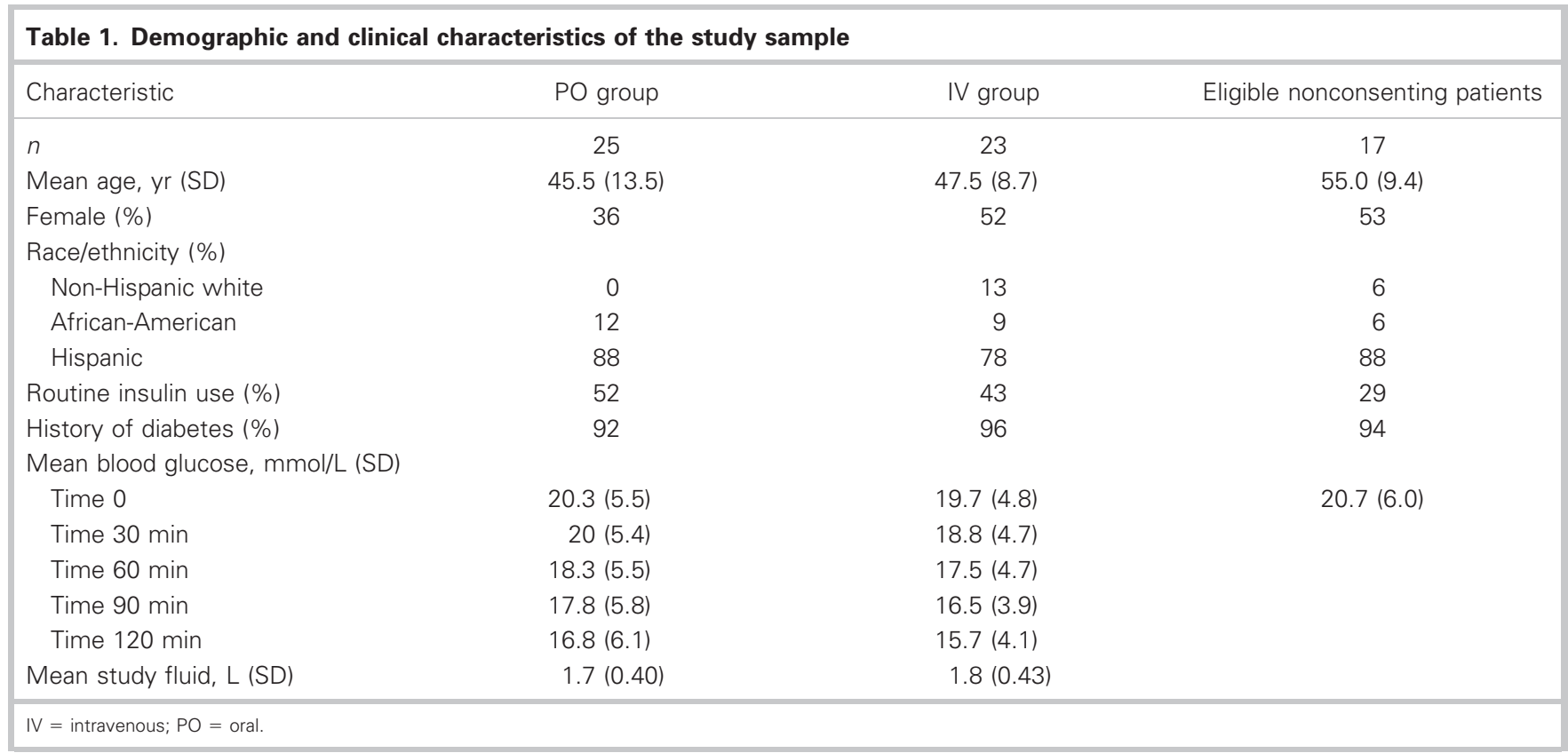

arms (Figure 1). No adverse events were observed in either group for the duration of the study period.

\section{DISCUSSION}

The number of patients in North America presenting to the ED with diabetes and diabetes-related complications is rising. ${ }^{1,2}$ Approximately one-quarter of ED patients have diabetes, and of these, almost half have poor glycemic control. ${ }^{1,3}$ As the prevailing attitude among ED health care providers is to "think worst first," common ED clinical practice is to consider the diagnosis of DKA in all patients presenting with an elevated triage blood glucose regardless of the reason for the visit. But in reality, only a very small proportion of these patients will screen positive for DKA or another metabolic emergency, making isolated hyperglycemia an extremely common clinical scenario. ${ }^{4}$ Although one could argue that the clinical importance and significance of acutely lowering blood glucose in

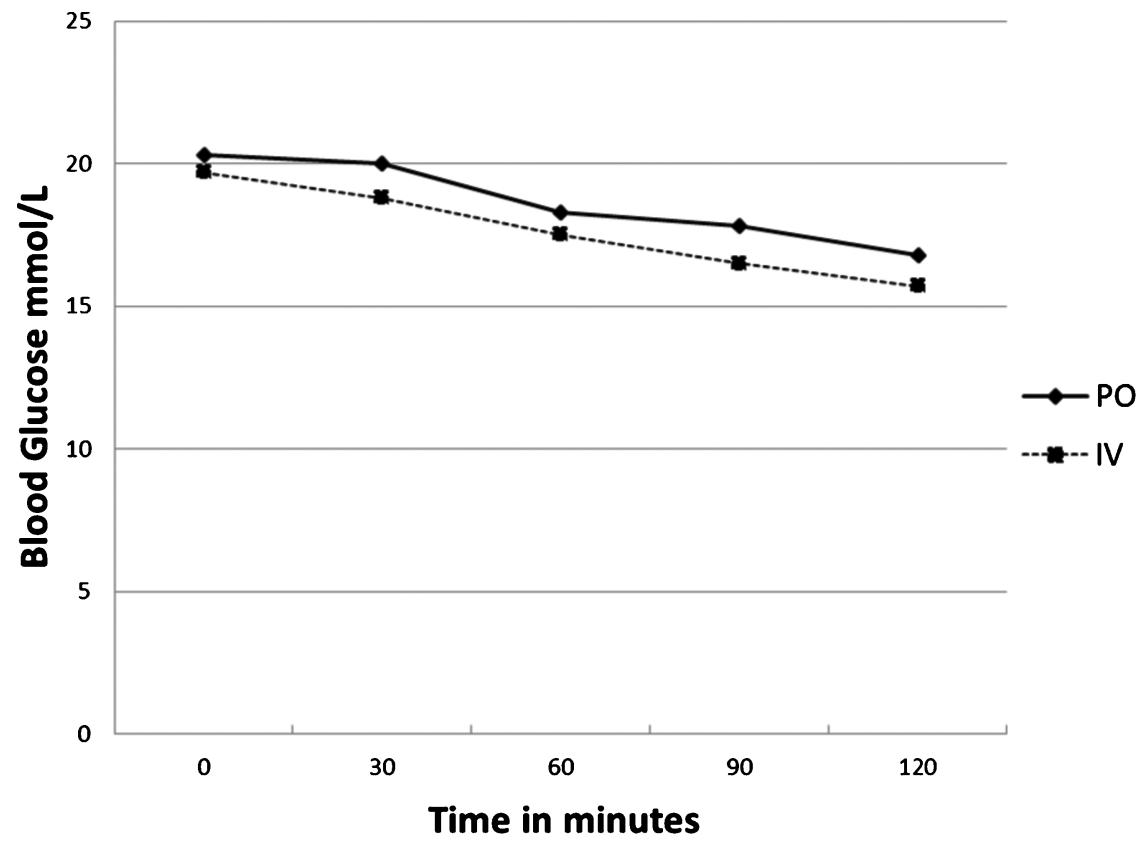

Figure 1. Change in mean blood glucose level across treatment arms. IV = intravenous; $\mathrm{PO}=$ oral. 
an asymptomatic hyperglycemic patient not in DKA are questionable, in practice, most emergency physicians feel uncomfortable discharging a patient with a persistently elevated blood glucose level. ${ }^{5}$ If we decide to act, we must choose between insulin and/or fluid administration. There are pros and cons to each treatment modality, but if we choose fluid therapy, there is no literature currently available evaluating the optimal route of administration. As ED overcrowding has stretched available resources to the breaking point, all therapies that have the potential to decrease ED length of stay and cost should be evaluated. But before cost and time outcomes can be evaluated, safety and efficacy must be established.

This is the first prospective, randomized, controlled trial to compare oral to IV fluid administration to reduce blood glucose values in stable ED patients with hyperglycemia. We found that both groups had modest decreases in blood glucose values during the study period $(3.4 \mathrm{mmol} / \mathrm{L}$ oral versus $4 \mathrm{mmol} / \mathrm{L} \mathrm{IV})$, and there was no significant difference across treatment arms at 2 hours $(-0.6 \mathrm{mmol} / \mathrm{L}, p=0.51)$. There were no observed complications in either group related to fluid therapy. This supports the notion that oral fluid administration may be an acceptable and safe alternative to IV fluids for the treatment of hyperglycemia. We did not compare the ability of oral or IV fluid to improve the hydration status of these patients as the purpose was to compare the ability of these therapies to lower blood glucose values. It is reasonable to believe that the two therapies may work equally well for rehydration in hyperglycemic patients based on previous literature comparing oral versus IV fluids in other acute illnesses (e.g., acute diarrheal illness). In a 2006 Cochrane review, Hartling and colleagues reviewed 17 clinical trials comparing IV and oral rehydration for children with acute gastroenteritis and found no significant difference in the time to rehydration or the need for admission. ${ }^{10}$ In their 2009 review, Atia and Buchman concluded that oral rehydration is safe and effective in both children and adults dehydrated from diarrheal illness. ${ }^{8}$ It should be noted that most studies in this parallel clinical problem used electrolyte enriched oral solutions, but hyperglycemia patients actually have a free water deficit due to osmotic diuresis, making oral water an appropriate hydration method.

Based on the aforementioned studies and others, it has become common clinical practice worldwide to use the oral route as a primary intervention for patients requiring fluids. ${ }^{8-10}$ Our findings suggest that the advantages or oral fluids observed in these other medical conditions (e.g., enteritis) requiring fluid therapy may also be applicable to the treatment of isolated hyperglycemia. These potential advantages of oral fluid administration over IV fluids include decreased nursing time, elimination of pain of $\mathrm{IV}$ insertion, earlier initiation of treatment, decreased ED length of stay, reduced cost, and increased patient and provider satisfaction. In the ED setting, it may even be possible to initiate oral fluid administration in the waiting room, conferring an additional benefit. These potential advantages were not specifically assessed in the present study of hyperglycemic patients as our focus was on safety and efficacy, but these should be the focus of future validation studies of our findings.

\section{LIMITATIONS}

This study is limited by a convenience sample of small size, limiting its power to detect a difference in the primary outcome. As we had no previous literature on which to estimate a treatment effect, we decided to choose a sample size based on available resources that would generate data for future studies. The difference between the two groups was small $(0.6 \mathrm{mmol} / \mathrm{L})$. We report a failure to consent rate of $26 \%$, which suggests a selection bias; however, the important covariates are similar across all eligible patients (see Table 1). The lack of blinding introduces potential bias into the study. This is minimized because the primary outcome of blood glucose is an objective measurement. It is possible that this lack of blinding did impact the research assistant's assessment of the presence of or a lack of adverse events, particularly due to our decision to use subjective clinical findings in lieu of more objective data (e.g., respiratory rate). We did not have a "no treatment" arm as our ED policy is to initiate fluid therapy on all hyperglycemic patients. We do not know if the blood glucose reduction measured in either group is more than would have been observed with time alone. We did not perform time or cost analyses to evaluate if oral fluid administration is faster or less expensive than IV fluids. Finally, we did not measure serum electrolyte concentrations before and after therapy in either group; however, we have been unable to find any literature or guidelines that support the concept that significant electrolyte abnormalities exist in patients with mild to moderate hyperglycemia 
without evidence of a concomitant acid-base disturbance (e.g., DKA).

\section{CONCLUSION}

Our results suggest that oral and IV fluids may be equally efficacious in lowering blood glucose levels in stable ED patients with hyperglycemia (initial blood glucose less than $33.3 \mathrm{mmol} / \mathrm{L}$ in our sample); however, a larger, adequately powered, blinded trial, with recruitment of a consecutive rather than a convenience sample, is required to compare this treatment strategy for equivalence. No adverse events were observed in either group. The utility of fluids in hyperglycemic patients is debatable, but as physicians often decide to initiate therapy, they should be mindful that, although similar, the reduction in blood glucose was modest in both groups.

Competing interests: None declared.

\section{REFERENCES}

1. Centers for Disease Control and Prevention, U.S. Department of Health and Human Services. National diabetes fact sheet. General information and national estimates on diabetes in the United States. Available at: http://www.cdc.gov.libproxy. usc.edu/diabetes/pubs/factsheet05.htm/ (accessed June 29, 2011).

2. Public Health Agency of Canada. Report from the Canadian Chronic Disease Surveillance System: diabetes in Canada, 2009.
Available at: http://www.phac-aspc.gc.ca/cd-mc/publications/ diabetes-diabete/facts-figures-faits-chiffres-2011/highlightssaillants-eng.php (accessed September 2012).

3. Menchine MD, Wiechmann W, Peters A, et al. Trends in diabetes-related visits to US EDs from 1997 to 2007. Am 7 Emerg Med 2012;30:754-8. [Epub 2011 May 12], doi:10. 1016/j.ajem.2011.02.028.

4. Ginde AA, Pelletier AJ, Camargo CA Jr. National study of U.S. emergency department visits with diabetic ketoacidosis, 1993-2003. Diabetes Care 2006;29:2117-9, doi:10.2337/dc060627.

5. Ginde AA, Delaney KE, Pallin DJ, et al. Multicenter survey of emergency physician management and referral for hyperglycemia. 7 Emerg Med 2010;38:264-70, doi:10.1016/ j.jemermed.2007.11.088.

6. Munoz C, Villaneuva G, Fogg B, et al. Impact of subcutaneous insulin protocol in the emergency department: Rush Emergency Department Hyperglycemia Intervention. (REDHI). 7 Emerg Med 2011;40:493-8, doi:10.1016/j. jemermed.2008.03.017.

7. Arora S, Cheng D, Wyler B, et al. Prevalence of hypokalemia in emergency department patients with diabetic ketoacidosis. Am 7 Emerg Med 2011 Feb 10. [Epub ahead of print]

8. Atia AN, Buchman AL. Oral fluid administration solutions in non-cholera diarrhea: a review. Am 7 Gastroenterol 2009; 104:2596-604, doi:10.1038/ajg.2009.329.

9. American Academy of Pediatrics. Practice parameter: the management of acute gastroenteritis in young children. Pediatrics 1996;97:424-35.

10. Hartling L, Bellemare S, Wiebe $\mathrm{N}$, et al. Oral versus intravenous fluid administration for treating dehydration due to gastroenteritis in children. Cochrane Database Syst Rev 2006;(3):CD004390. 